\title{
Custom-made Gold Implant for Management of Lagophthalmos: A Case Report
}

\author{
Suleyman Hakan Tuna \\ Hasan Onder Gumus ${ }^{b}$ \\ Nur Hersek ${ }^{c}$
}

\begin{abstract}
Lagophthalmos is defined as the inability to close the eyelids completely. This situation may lead to corneal problems such as epithelial defects, stromal thinning, exposure keratitis, bacterial infection, perforation, and blindness. A patient with lagophthalmos underwent insertion of a custommade gold weight implant. After implantation, the patient was able to close her eye and expressed high cosmetic and aesthetic results. Fabrication of gold weight implant by the means of a rolling machine is an effective and easy way and should be considered in the management of lagophthalmos. (Eur J Dent 2008;2:294-298)
\end{abstract}

Key words: Lagophtalmos; Orbicularis oculi muscle; Eyelid; Gold weight implant.

\section{INTRODUCTION}

Lagophthalmos is defined as the inability to close the eyelids completely. ${ }^{1,2}$ Orbicularis oculi muscle that closes eyelids is innervated by facial nerve (CNVII). Paresis of the orbicularis oculi muscle leads to diminished blink, lagophthalmos, and impairment of the nasolacrimal pumping

a Assistant Professor, Department of Prosthodontics, Faculty of Dentistry, Süleyman Demirel University, Isparta, Turkey.

b Lecturer, Department of Prosthodontics, Faculty of Dentistry, Erciyes University, Kayseri, Turkey.

Professor, Department of Prosthodontics, Faculty of Dentistry, Hacettepe University, Ankara, Turkey.

- Corresponding author: S. Hakan Tuna Suleyman Demirel Universitesi, Dis Hekimligi Fakultesi, Protetik Dis Ted. AD. Cunur, Isparta, Turkey. Phone: +902462113234 Fax: +902462370607 E-mail: shtunalahotmail.com system. Lagophthalmos may be the result of the residual effect of seventh cranial nerve damage secondary from congenital (moebius' syndrome), acquired (Bell's palsy, vascular lesions), tumors, iatrogenic (during surgery), trauma, infections, or degenerative diseases., The blink reflex and lid closing are critical to maintain the ocular health. Each blink spreads the tear film over the ocular surface and allows a continuous layer of moisture. The inability to close the eyelid may lead to corneal problems such as epithelial defects, stromal thinning, exposure keratitis, bacterial infection, perforation, and blindness. ${ }^{5-9}$

The prior treatment of lagophthalmos is conservative and symptomatic such as ointments, eye drops, taping, and moisture chambers. Surgical intervention may be required in patients who have failed medical therapy or 
in whom the facial paralysis is not expected to improve. ${ }^{5}$ Upper lid loading in the treatment of paralytic lagophthalmos brings out the highest patient satisfaction in lid closing during the day and during sleep as well as in the aesthetic appearance of the lid. When implanted into lid margin, the weight will essentially allow earth's gravity to gently pull the eye to the closed position when the muscles relax.

In this procedure, a gold weight is inserted in the upper eyelid to allow closure by the force of gravity. The presence of the weights seems to contribute to the mimics and blinking of the eyelids which provides a better aesthetic appearance.

Gold is the preferred material due to its color, specific gravity, and tissue compatibility. 2,9-12 Gold weight eyelid implants can elicit a gradually progressive inflammatory response. In at least some cases, local corticosteroid injection may suppress the inflammation and permit retention of the implant. ${ }^{13}$ Common complications are related to the selection of wrong weight, and insufficient or excessive correction. ${ }^{14}$

The eyelid implant method of treatment has proven to be very successful, easily accomplished, and one that may involve the dental profession. ${ }^{6}$

In this case report the treatment method of the paralyzed eyelid of a patient by a gold weight implant was explained.

\section{CASE REPORT}

A 35-year-old Caucasian woman, applied to our department for consultation due to the development of lagophthalmos at her left eyelid 6 months ago caused by acoustic neuroma (Figure 1). Gold weight implantation to left upper lid was planned for solution of the problem.

To determine the weight of the implant, a container was tied to a string and was attached to the eyelid (Figure 2).Container was made of a plastic amalgam capsule (Permite, SDI, Australia). When the patient's head was at upright position, mercury (Gulsa, Atlas- Enta, İzmir, Turkey) was dropped step by step into the container and the patient was instructed to close her eyes. Mercury was preferred due to its specific gravity and easy manuplation. The container including mercury and string and sticking plaster weighted by a jewellery balance (Radwag WPX 250, Radom, Poland). The load at which the patient was able to close her eyelid was weighted to be $1.1 \mathrm{~g} ; 0.2 \mathrm{~g}$ was added to this amount and the final weight of the implant was calculated as $1.3 \mathrm{~g}$.

Irreversible hydrocolloid impression material (Kromopan 100, Lascod, S.p.A., Florence, Italy) was used to make the impression and a plaster model was obtained on this model, the implant design was made and the plaster was trimmed arbitrarily (Figure 3). The patient's affected eyelid was protected with a sticky band-aid, during the impression procedure.

Commercially available $2.5 \mathrm{~g}$ square shaped pure gold (99.99\%), (Ziraat Bank, Turkey), was wrought by a Rolling machine, (Lion Gold Smith Production, Model No: MRMC 001, Gujarat, Indial than trimmed to a desired shape. Wrought and trimming procedures gradually performed until the defined shape and weight is attained.

This gold piece was placed on the plaster model and the margins were trimmed and burnished thus the form of the curvature was given. Two holes were drilled on the gold plate to fix the suture during the surgery. After polishing, final weight of gold plate was verified the procedure was completed. Gold implant was tried on the patient by the help of a both side sticky tape. After ultrasonic cleaning with ethanol solution, the gold implant was delivered to the surgeon for sterilization and insertion.

The gold weight implant was inserted and fixed by plastic surgeons to the tarsal plate (Figures 4 and 5). A protective pad was applied to cover the eyelid. Patient's complete eyelid closure and restoration of blink reflex were obtained at postoperative examination. Corneal irritation symptoms were not observed after the procedure.

After the healing phase of the edema on the eyelid (Figure 6), the patient was instructed to exercise to close her eyelid manually. The patient was able to close her eye and pleased with the cosmetic and esthetic results after three months and 2 years control trial.

\section{DISCUSSION}

Gold weight implantation is the most commonly used static procedure and method for surgical correction of paralytic lagophthalmos. .,15 $^{2}$ Other mechanical techniques for reanimating lid closure are palpebral springs, encircling the 
upper and lower eyelids with silicone or fascia lata, and temporalis muscle transfer. ${ }^{15}$ Although other materials are also used, gold weights are frequently preferred because of gold's high specific gravity, inertness to the body and malleability. ${ }^{4}$ Especially platinum weights should be used in patients with suspected gold allergy. ${ }^{11}$

The use of gold weight eyelid implants is certainly a desirable option for treatment of patients suffering from lagophthalmos, but it is not always successful or may not give the desired aesthetic result due to the thickness of the prefabricated implants and the anatomical

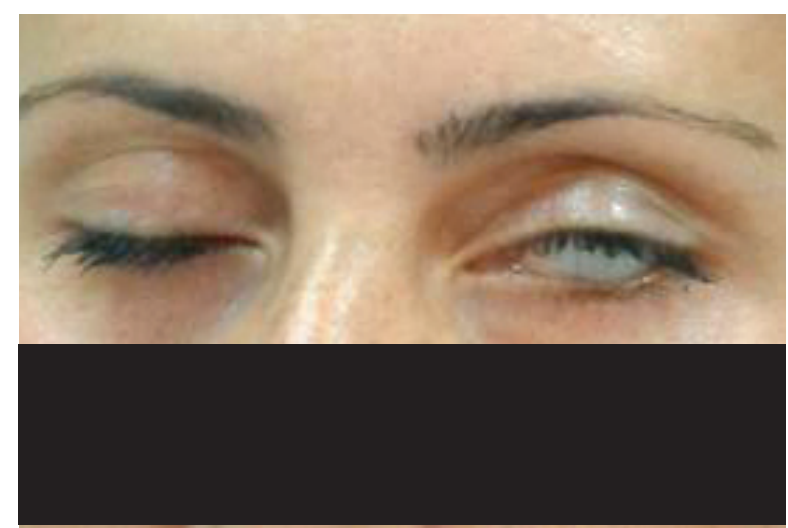

Figure 1. Initial frontal view; the left cornea remains exposed.

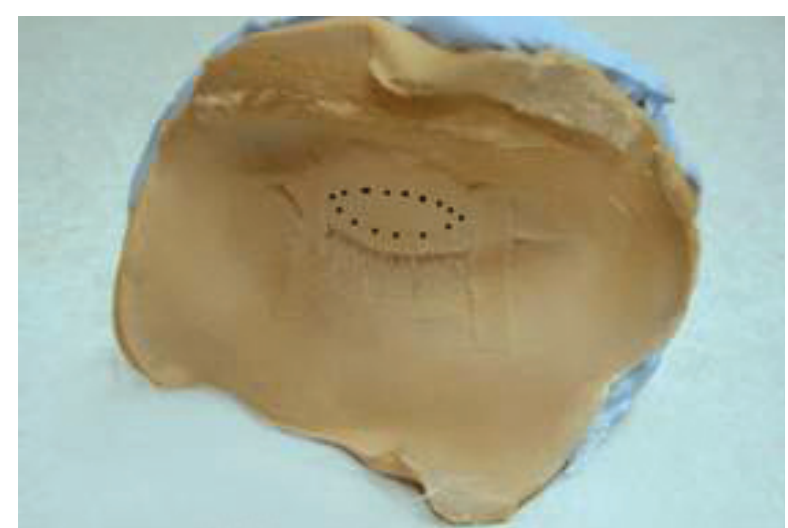

Figure 3. Plaster model: gold weigh design planned.



Figure 5. Appearance of eyelid during the healing phase. structures of the eye. There are distinct anatomic differences between the Caucasian and Asian eyelids, which dictate the overlying aesthetic differences. ${ }^{5}$ Commercially manufactured gold implants are available in several weights and are usually used but may create a "brick-like" appearance within the eyelid. Custom-made weights that produce a much more aesthetic result can be fabricated by the dental professionals. ${ }^{6}$

The gold weight trial procedure was considered a success when postoperative lagophthalmos met the predefined preoperative success criteria Iminimum $50 \%$ reduction in lagophthalmos without

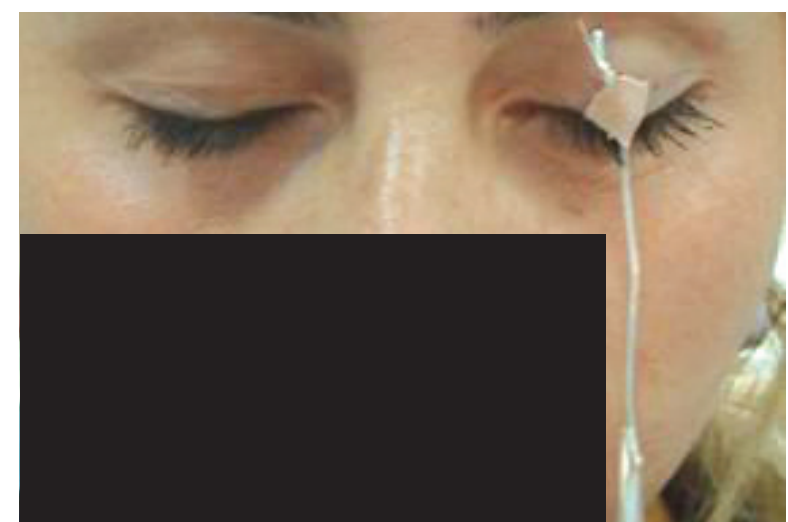

Figure 2. Mercury container attached to left eyelid with a sticky tape.

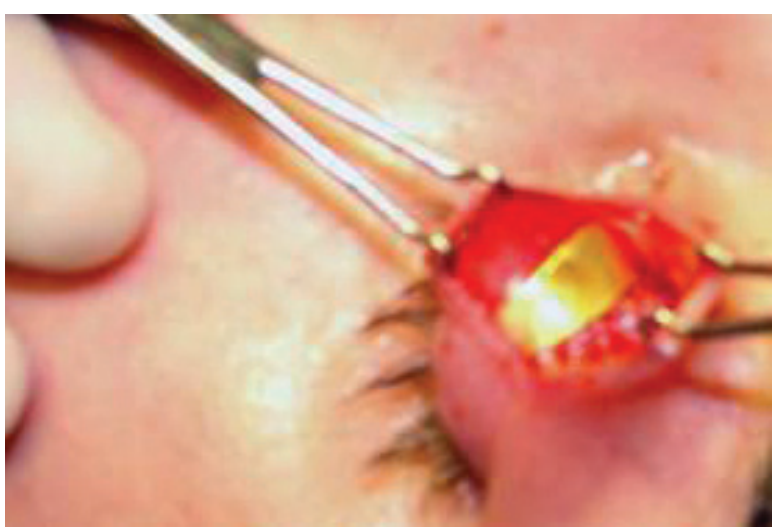

Figure 4. Insertion of gold weight during surgery.



Figure 6. Appearance of eyelid two years after the surgery. 
induction of $>2 \mathrm{~mm}$ ptosis) and was considered a failure when the reduction in the lagophthalmos did not reach $50 \%$ of the preoperative value. ${ }^{16}$

Adequate preoperative evaluation is necessary to determine optimum size, weight, and position of the gold implant. ${ }^{11}$ The most common complications result from inappropriate gold weights. The insufficient gold weight is not effective for closing the eyelid; contrary excessive estimation leads to unaesthetic appearance and ptosis of the eyelid. However, it is also frequently associated with certain complications like ulceration, migration, extrusion, etc. ${ }^{17}$ At the present case, care was taken to find the appropriate weight before the operation. As a result, the selected weight and curvature of the gold implant was unique to patient, and there were no complications during the follow-up period of at least 2 years.

Kelly and Sharpe suggested that the implants must be fabricated in perforated design to allow tissue penetration and to prevent migration. ${ }^{18}$ It was also reported that gold implants which do not adapt the slope of cornea cause astigmatism..$^{8,19}$ Our patient did not complain of any visual discomfort. Because of the aforementioned complications due to fabricated weighs, we preferred a custom-made gold weigh implant.

The estimated weight of the implant from the trials on the skin of the upper lid fails to obtain the expected eye closure outcomes after surgical implantation on the tarsal plate. ${ }^{20}$ The results show that an addition of $0.2 \mathrm{~g}$ to the gold weight estimated in the trial is required to achieve a similar closure of the eye by means of the gold implant on the tarsal plate. ${ }^{20}$

Smellie suggested 0.75 to $1.0 \mathrm{~g}$ of lid loading for most effective eyelid closure, whereas Gilbard and Daspit concluded that a much heavier weight $(1.2$ to $2.6 \mathrm{~g})$ is required to achieve complete lid closure. ${ }^{21,22}$ According to Aggarwa et al the median predicted ideal gold weight was $1.2 \mathrm{~g}$ (range, 1.0 to 2.0 g). ${ }^{16}$ In this case the gold weight was $1.3 \mathrm{~g}$.

Usually to fabricate the gold implant at the determined weight, the density of the gold and the weight of the wax pattern is helpful for calculation. ${ }^{23}$ In this case casting procedures and related failures were easily eliminated by using a rolling machine.

\section{CONCLUSIONS}

A custom-made gold weigh eyelid implant can be fabricated by the means of a rolling machine. By this way casting procedures and related failures were easily eliminated. Fabrication of gold weight implants with the aid of a rolling machine is an effective and easy way and should be considered in management of lagophthalmos. In the present case, management of lagophthalmos was easily accomplished with a custom-made gold implant.

\section{REFERENCES}

1. Cline D, Hofstetter HW. Dictionary of visual science. 4th ed Boston: Butterworth-Heinemann; 1997.

2. Grisius MM, Hof RL. Treatment of lagophthalmos of the eye with a custom prosthesis. J Prosthet Dent 1993;70:333335.

3. Rubin LR, Lee GW, Simpson RL. Reanimation of the long-standing partial facial paralysis. Plast Reconstr Surg 1986;77:41-49.

4. Sonmez A, Ozturk N, Durmus N, Bayramicli M, Numanoglu A. Patients' perspectives on the ocular symptoms of facial paralysis after gold weight implantation. J Plast Reconstr Aesthet Surg 2008;61:1065-1068.

5. Choo PH, Carter SR, Seiff SR. Upper eyelid gold weight implantation in the Asian patient with facial paralysis. Plast Reconstr Surg 2000;105:855-859.

6. Choi M, Driscoll CF. Fabrication of a custom eyelid implant prosthesis: a clinical report. J Prosthodont 2004;13:101103.

7. Kao $\mathrm{CH}$, Moe KS. Retrograde weight implantation for correction of lagophthalmos. Laryngoscope 2004;114:15701575.

8. Mavrikakis I, Beckingsale P, Lee E, et al. Changes in corneal topography with upper eyelid gold weight implants. Ophthal Plast Reconstr Surg 2006;22:331-334.

9. Snyder MC, Johnson PJ, Moore GF, Ogren FP. Early versus late gold weight implantation for rehabilitation of the paralyzed eyelid. Laryngoscope 2001;111:2109-2113.

10. Demann ET, Stein PS, Haubenreich JE. Gold as an implant in medicine and dentistry. $J$ Long Term Eff Med Implants 2005;15:687-698.

11. Dinces EA, Mauriello JA, Jr., Kwartler JA, Franklin M. Complications of gold weight eyelid implants for treatment of fifth and seventh nerve paralysis. Laryngoscope 1997; 107:1617-1622 
12. Tremolada C, Raffaini M, D'Orto O, et al. Temporal galeal fascia cover of custom-made gold lid weights for correction of paralytic lagophthalmos: long-term evaluation of an improved technique. J Craniomaxillofac Surg 2001;29:355359.

13. Bair RL, Harris GJ, Lyon DB, Komorowski RA. Noninfectious inflammatory response to gold weight eyelid implants. Ophthal Plast Reconstr Surg 1995;11:209-214.

14. Dalkiz M, Gokce HS, Aydin A, Beydemir B. Gold weight implantation for rehabilitation of the paralysed eyelid. Int J Oral Maxillofac Surg 2007;36:522-526.

15. Nazzi V, Marras C, Broggi G. Upper eyelid gold weight implants in patients with facial nerve palsy. Surgical technique. J Neurosurg Sci 2006;50:107-110.

16. Aggarwal E, Naik MN, Honavar SG. Effectiveness of the gold weight trial procedure in predicting the ideal weight for lid loading in facial palsy: a prospective study. $A m J$ Ophthalmol 2007;143:1009-1012.

17. Bhatti AF, Page $K$, Orlando A. Modification of the goldweight implant for insertion into the upper eyelid in facial palsy. Ann Plast Surg 2005;55:689-692.

18. Kelley SA, Sharpe DT. Gold eyelid weights in patients with facial palsy: a patient review. Plast Reconstr Surg 1992;89:436-440.

19. Patel BC, Flaharty P, Anderson RL. Morbidity after gold weight insertion. Br J Plast Surg 1993;46:343-344.

20. Hontanilla B. Weight measurement of upper eyelid gold implants for lagophthalmos in facial paralysis. Plast Reconstr Surg 2001;108:1539-1543.

21. Smellie GD. Restoration of the blinking reflex in facial palsy by a simple lid-load operation. Br J Plast Surg 1966;19:279283.

22. Gilbard SM, Daspit CP. Reanimation of the paretic eyelid using gold weight implantation. A new approach and prospective evaluation. Ophthal Plast Reconstr Surg 1991;7:93-103.

23. Sela M, Taicher S. Restoration of movement to the upper eyelid in facial palsy by an individual gold implant prosthesis. J Prosthet Dent 1984;52:88-90. 